\title{
OPEN
}

\section{Retraction Note: Simulation and spatiotemporal pattern of air temperature and precipitation in Eastern Central Asia using RegCM} Xianyong Meng $\mathbb{1}^{1}$, Aihua Long ${ }^{1}$, Yiping Wu $\mathbb{1}^{2}$, Gang Yin ${ }^{3}$, Hao Wang ${ }^{1}$ \& Xiaonan $\mathrm{Ji}^{3}$

Retraction of: Scientific Reports https://doi.org/10.1038/s41598-018-21997-4, published online 26 February 2018

The authors are retracting this Article.

In this study, we used RegCM to downscale the ERA40 and NCEP climate data in the Xinjiang area, and then compared the simulated data with extrapolated data from CRU.

Extrapolated data were used because using observational data would have led to poor performance of the model, RegCM. As a result, conclusions reported in the paper - increasing precipitation in South Tianshan, and a decreasing trend in the north - are unsupported, and are misleading to the research community and the public. Therefore, we are retracting this article. We apologize for the inconvenience caused.

All authors agree with the retraction.

(i) Open Access This article is licensed under a Creative Commons Attribution 4.0 International License, which permits use, sharing, adaptation, distribution and reproduction in any medium or format, as long as you give appropriate credit to the original author(s) and the source, provide a link to the Creative Commons license, and indicate if changes were made. The images or other third party material in this article are included in the article's Creative Commons license, unless indicated otherwise in a credit line to the material. If material is not included in the article's Creative Commons license and your intended use is not permitted by statutory regulation or exceeds the permitted use, you will need to obtain permission directly from the copyright holder. To view a copy of this license, visit http://creativecommons.org/licenses/by/4.0/.

(C) The Author(s) 2019

\footnotetext{
${ }^{1}$ State Key Laboratory of Simulation and Regulation of Water Cycle in River Basin \& China Institute of Water Resources and Hydropower Research, Beijing, 100038, P. R. China. ${ }^{2}$ Department of Earth \& Environmental Science, Xi'an Jiaotong University, Xi'an, Shaanxi Province, 710049, P. R. China. ${ }^{3}$ Xinjiang Institute of Ecology and Geography, Chinese Academy of Sciences, Urumqi, 830011, P. R. China. Correspondence and requests for materials should be addressed toX.M. (email: mxy@iwhr.com) or A.L. (email: ahlong@iwhr.com) orY.W. (email: yipingwu@xjtu.edu.cn)
} 